\title{
POLÍTICAS PÚBLICAS DO ENSINO DE LITERATURA NAS ESCOLAS: Algumas Discussões Acerca da Literatura e a Sua Prática
}

\author{
Mess Lane de Souza Bello ${ }^{1}$ \\ Raquel Aparecida Dal Cortivo ${ }^{2}$
}

\begin{abstract}
RESUMO
Num contexto no qual se noticia vigorosamente o baixo aproveitamento dos alunos na leitura, torna-se fundamental refletir sobre o ensino de literatura na escola e as políticas públicas de ensino que a envolvem. Dessa forma, urge refletir a respeito das políticas públicas voltadas para o ensino de literatura no contexto escolar, a partir de uma discussão que passa pelos sentidos que a palavra literatura foi ganhando com o passar do tempo e pelos discursos teóricos mais atuais sobre a literatura, que permitem revisitar algumas correntes críticas de modo a compreender de maneira mais ampla o conceito de texto literário. A discussão acerca do papel da literatura na sociedade permite pontuar algumas considerações sobre o ensino de literatura, confrontadas com documentos oficiais. As discussões aqui realizadas partem de um estudo bibliográfico e análise dos documentos oficiais que regem o ensino de maneira geral e de literatura em específico. Constatou-se que o significado do termo Literatura passou por diversas transformações, e a compreensão sobre sua função social, cultural e formativa foi modificando-se com o passar do tempo.
\end{abstract}

Palavras-Chave: Ensino. Escola. Literatura. Políticas públicas.

PUBLIC POLICIES FOR LITERATURE TEACHING IN SCHOOLS: SOME DISCUSSIONS ABOUT LITERATURE AND ITS PRACTICE

\begin{abstract}
In a context in which students' low reading performance is vigorously reported, it is essential to reflect on the teaching of literature at school and the public teaching policies that involve it. Thus, there is an urgent need to reflect on public policies aimed at teaching literature in the school context from a discussion that goes through the meanings that the word literature has gained over time and the most current theoretical discourses about literature that they allow us to revisit some critical currents in order to understand the concept of literary text more broadly. The discussion about the role of literature in society allows to point out some considerations about teaching literature, compared to official documents. The discussions held here start from a bibliographic study and analysis of the official documents that govern teaching in general and literature in particular. It was found that the meaning of the term Literature has undergone several transformations and the understanding of its social, cultural and formative function has changed over time.
\end{abstract}

Keywords: Teaching. School. Literature. Public policy.

Recebido em: 4/2/2020

Aceito em: 20/4/2020

\footnotetext{
1 Mestre em Ensino de Ciências e Humanidades pela Universidade Federal do Amazonas. Graduação em Letras pela Universidade Federal do Amazonas (2017). Tem experiência na área de Letras, com ênfase em Língua Portuguesa, trabalhando com o tema literatura Brasileira. http://lattes.cnpq.br/5428537942899456. https//orcid.org/0000-0002-9585-090X. misslane_samuel@hotmail.com

2 Graduação em Letras pela Universidade Federal de Rondônia (1998). Mestrado em Letras Teoria Literária São José do Rio Preto pela Universidade Estadual Paulista Júlio de Mesquita Filho (2002). Doutorado em Estudos Comparados de Literaturas de Língua Portuguesa pela Universidade de São Paulo (FFLCH, 2016). Professora-adjunta da Universidade Federal do Amazonas. Tem experiência na área de Letras, com ênfase em Teoria Literária, atuando principalmente nos seguintes temas: teoria literária, literatura comparada, literatura brasileira, estudos comparados e poesia brasileira. http://lattes.cnpq.br/1104061269028718. https//orcid.org/0000-0002-6050-8434 raqueldalcortivo@gmail.com
} 
Dentro do contexto escolar existem elementos que contribuem diretamente no processo de ensino e aprendizagem. Dentre esses, temos as disciplinas com determinadas cargas horárias, metodologias e ferramentas pedagógicas. Nesse contexto, a Literatura, como parte do ensino do nível médio, precisa ser revista e refletida no sentido de pensar a sua prática e de como ela é articulada na relação entre professor e conteúdo e, consequentemente, entre conteúdo e aluno.

Os alunos passam a ter o ensino da Literatura agregado à Língua Portuguesa, ou seja, fica a cargo do professor de Língua Portuguesa a quantidade de aulas que abordará os conteúdos da Literatura, a serem ministradas durante a semana, sendo entre uma ou duas aulas. Essas disciplinas fazem partem dos Parâmetros Curriculares Nacionais da área de Linguagens, Códigos e suas Tecnologias (BRASIL, 2010). O grande problema é que o ensino da Literatura nesse nível ocorre de forma limitada, conservadora e fragmentada, em que o processo histórico é o principal foco. Tais procedimentos são baseados unicamente no livro didático, no intuito de regulamentar uma leitura mecânica, reduzindo as múltiplas possibilidades de reflexões e discussões acerca de determinada temática ou obra.

A Literatura no Ensino Médio deve ser proporcionada de forma que os alunos não tenham apenas o contato com variados livros e autores, mas uma reflexão formativa e crítica a partir dos textos ficcionais, a fim de levá-los a compreender a forma como os textos estabelecem relação com as mais variadas situações sociais e individuais.

Lajolo (2002) destaca que o contato com a literatura constitui um campo privilegiado da leitura, contribuindo na ampliação do conhecimento e da realidade em que o aluno atua. Já Compagnon (2010) destaca os dois lados da literatura, que ora entra em consonância com o status quo, ora se torna revolucionária. Às vezes, vista como contribuidora de uma ideologia dominante, comanda o consenso, e, em outros momentos, contestadora dessa ideologia, opta pelo novo, pela ruptura.

Nesse sentido, a partir da discussão sobre os diversas definições que a Literatura foi ganhando no decorrer dos tempos e em razão das variadas abordagens teóricas, a pesquisa em questão tem como objetivo geral refletir sobre as políticas públicas voltadas para o ensino de literatura no contexto escolar, e, como objetivos específicos, pretende discutir sobre os sentidos que a palavra literatura foi ganhando ao passar dos tempos; destacar os discursos teóricos mais atuais sobre a literatura; revisitar algumas correntes teóricas de forma a compreender a visão mais ampla sobre o conceito de texto literário; e pontuar algumas considerações sobre o ensino de literatura a partir de alguns documentos oficiais.

\section{LITERATURA: DISCUSSÕES ACERCA DO TERMO}

Etimologicamente advinda do latim, a palavra literatura significa escrita, gramática, ciência. No século 16 ganha teor cultural, isto é, ter literatura era possuir cultura e privilégio de homens letrados, pois eles realizavam uma gama de leituras. Tal termo, então, acaba vinculando-se a determinado grupo, os de letras. O conceito da palavra, portanto, era amplo e se referia a tudo o que era escrito. Conforme elucida Jouve (2012), "diante da necessidade de um termo geral para designar a arte de escrever, os olhares se voltaram para a palavra literatura (p. 30). A literatura antes limitava-se à poesia; no 
século 18 começa-se a trabalhar a ideia da arte da linguagem, e é nesse século que surgem os gêneros nomeados como vulgares, a saber, o romance e a prosa vinda do jornalismo.

As discussões acerca do termo tratadas pela teoria literária são extensas; vão além da acepção do termo literatura e investigam sua "natureza" a partir da pergunta central para a área: O que é literatura? Muitas obras teóricas tentam defini-la, apontando seu sentido ficcional. Pode-se afirmar que a literatura, nessa perspectiva, é dotada de um teor imaginativo, ou seja, não tem veracidade. Tal definição, todavia, é insuficiente, pois obriga a questionar o próprio conceito de verdade, cujos limites podem expandir-se para além do fato histórico. Terry Eagleton (2006, p. 3) alerta que

\begin{abstract}
Talvez nos seja necessária uma abordagem totalmente diferente. Talvez a literatura seja definível não pelo fato de ser ficcional ou "imaginativa", mas porque emprega a linguagem de forma peculiar. Segundo essa teoria, a literatura é a escrita que, nas palavras do crítico russo Ramon Jakobson, representa uma "violência organizada contra a fala comum". A literatura transforma e intensifica a linguagem comum, afastando-se da fala cotidiana. Se alguém se aproximar de mim em um ponto de ônibus e disser: "Tu, noiva ainda imaculada da quietude", tenho consciência imediata de que estou em presença do literário.
\end{abstract}

A definição de literatura, nessa perspectiva, não se dá pelo significado do texto ou seu conteúdo, mas pela forma que o texto assume, ou seja, a maneira que o texto expressa o conteúdo. As palavras contidas na frase literária ultrapassam o sentido abstrato. De forma mais técnica, os linguistas afirmam que a arbitrariedade entre os significantes e significados é, de algum modo, atenuada. É uma linguagem que chama atenção, vivificada por uma existência material, diferente da linguagem cotidiana.

Esse conceito de literário surge com os estudos dos formalistas russos que propõem uma abordagem do texto literário desvinculada de elementos externos. Preocuparam-se, então, com qualidade do texto, ou seja, o texto vale por si. A literatura não era embutida de religião, psicologia, sociologia ou filosofia, mas valorizada pela organização da linguagem que continha. A leitura da obra literária era regrada e tinha seus mecanismos de interpretações limitados pelos elementos que o texto fornecia. Eagleton (2006, p. 4) elucida que, nessa perspectiva, "a obra literária não era um veículo de ideias, nem uma reflexão sobre a realidade social, nem a encarnação de uma verdade transcendental: era um fato material, cujo o funcionamento podia ser analisado mais ou menos como examina uma máquina".

Essa ideia de literatura como um objeto autônomo, cujo significado depende apenas de sua organização, embora tenha o mérito de colocar em evidência o próprio texto, apresenta limites e problemas a serem superados, principalmente na reabilitação da literatura na escola. O que compreendemos até então é a tentativa de definir o que é literatura. Enquanto muitos teóricos ainda defendem aspectos formais valorizados anteriormente, outros contemporâneos tentam quebrar velhos paradigmas para valorizar obras não consideradas canônicas.

Assim, emergem questionamentos, como os apresentados por Compagnon (2010, p. 25): 
O que é literatura?

Qual é a relação entre literatura e autor?

Qual é a relação entre literatura e realidade?

Qual é a relação entre literatura e autor?

Qual é a relação entre literatura e linguagem?

Conforme ressalta o autor, a multiplicidade das respostas possíveis aponta para opções que se configuram, no contexto escolar para o qual se volta nossa explanação, como escolhas políticas, pelo fato de determinarem, de alguma forma, não somente o trabalho com o texto literário, mas também os discursos em torno da literatura. Compagnon (2010, p. 26) pondera:

[...] em outras palavras, várias respostas são possíveis, não compossíveis, aceitáveis, não compatíveis; ao invés de se somarem numa visão total e mais completa, elas se excluem mutuamente, porque não chamam de literatura, não qualificam como literária a mesma coisa; não visam a diferentes aspectos do mesmo objeto, mas a diferentes objetos. Antigo ou moderno, sincrônico ou diacrônico, intrínseco ou extrínseco: não é possível tudo ao mesmo tempo. Na pesquisa literária, "mais é menos", motivo pelo qual devemos escolher. Além disso, se amo a literatura, minha escolha já foi feita. Minhas decisões literárias dependem de normas extraliterárias - éticas, existenciais - que regem outros aspectos da minha vida.

As concepções dos estudos literários explicitam o conceito de literatura nas suas mais diversas formas, não obstante concordam em um ponto: têm o texto literário como seu objeto de estudo. Compagnon (2010) discute a relação do texto literário com outras seis noções: da intenção, da realidade, da recepção, da língua, da história e do valor. Dentre tais reflexões, discute-se a questão da literariedade, ou seja, a forma do texto, a sua estética, que estabelece padrões de valoração para o estabelecimento de um cânone. Vários críticos contemporâneos, porém, têm levantado questões acerca do que se entende por literariedade e os critérios envolvidos na formação do cânone. Além de Compagnon (2010), outra crítica, Marcia Abreu, em sua obra Cultura letrada: literatura e leitura (2006, p. 29), defende que "[...] a literariedade não está apenas no texto - os mais radicais dirão: não está nunca no texto - e sim na maneira como é lido. Um "mesmo" texto ganha sentidos distintos de acordo com aquilo que se imagina que ele seja: uma carta ou um conto, um poema ou uma redação".

Vários discursos ainda pautam sobre a função da literatura; do que deve ser visto ou não como texto literário. Tendências surgem com o intuito de quebrar com velhos paradigmas ou formas de ver o texto, ou de construir um novo acervo no qual outras manifestações literárias sejam incluídas. A tendência de desmistificar, principalmente que a arte tem um fim em si mesma, foi articulada, impulsionando outras manifestações importantíssimas para adentrar nas esferas sociais menos favorecida. O Pós-Colonialismo e os Estudos Culturais são tendências críticas que abrem essas portas antes fechadas.

\section{A teoria crítica pós-colonialista}

Ao pensar na teoria e na crítica pós-colonialista, temos uma tendência crítica que apresenta uma percepção estética renovada, em que o texto, apoiado por uma interpretação política, se assim podemos nomear, é perpassado pelas forças que embasam 
o contexto de sua produção, o discurso e o poder. O pós-colonialismo tem sua premissa no século 20, fruto de um panorama constituído de populações que estavam submetidas ao colonialismo europeu, negros e descendentes de escravos, expostos à discriminação e com direitos negados. O cenário em questão compreendia, também, uma grande porcentagem da população feminina. condicionada a uma conjuntura patriarcalista: o poder centralizado pela raça branca masculina, seja ele político ou econômico, restrito especificamente à classe rica e cristã.

Apesar de nebuloso, entretanto, este quadro propiciou, por outro lado, "[...] a nítida consciência da subjetividade política-cultural e da resistência de povos e nações contra qualquer tentativa para manter a objetificação ou iniciar uma nova modalidade de dependência" (BONNICl, 2009, p. 260), com a resistência como modelo impulsionador de imposições advindas das metrópoles.

Muitos movimentos intensificaram essa postura e colaboraram de forma incisiva no pensamento pós-colonialista. Segundo Bonnici (2009, p. 260),

O Renascimento do Harlem (movimento cultural e literário entre os escritores e artistas norte-americanos, especialmente na cidade de Nova lorque, cuja finalidade foi realçar o interesse na cultura africana ao redor do mundo) nos Estados Unidos nas décadas de 1920 e 1930 mostra a recusa em deixar a cultura eurocêntrica, cristã e branca continuar definindo o outro ${ }^{3}$ em geral e a população afro-americana em particular (APPIAH; GATES, 1997). Idêntica atitude estava por trás do movimento Négritude ${ }^{4}$ na década de 1930 em vários países africanos. Essa tendência para a autodeterminação dos povos em todos os aspectos teve um recrudescimento, após a Segunda Guerra Mundial, especialmente nos movimentos pelos Direitos Civis nos Estados Unidos e na luta contra o colonialismo britânico, francês, português, alemão, belga em todos os continentes.

Os dois movimentos aludidos são de grande teor político, cultural e literário, tendo em vista suas grandes implicaturas nos estudos pós-coloniais. O Renascimento do Harlem e a Negritude foram importantes no processo de descolonização; agitações precursoras da expansão de outras lutas emancipatórias. É valido lembrar que, historicamente, no último período do século 18 e no primeiro período do 19, os escritores brasileiros produziram com vasta inserção de temas nacionais, que seguiam padrões europeus, mas foi o "Modernismo brasileiro, contudo, iniciado na década de 1920 e suas subcorrentes que apresentaram propostas de uma arte essencialmente brasileira" (BONNICl, 2009, p. 226).

No que se refere à crítica em relação ao termo pós-colonialismo, há duas perspectivas: a dos autores tradicionais e a dos modernos. Corrobora Bonnici (2012, p. 19):

\footnotetext{
3 "Deriva-se o conceito de Outro/outro da filosofia de Sartre, da formação de sujeito de Freud e de Lacan. Aplicando a teoria lacaniana ao pós-colonialismo, pode-se dizer que o Outro se refere ao centro e ao discurso imperial, enquanto o outro adquire sua identidade de colonizado [...]" (BONNICl, 2005, p. 45).

4 Para maiores esclarecimentos e entendimentos do movimento e conceito de Negritude, consultar CÉSAIRE, Aimé. Discurso sobre a negritude. Belo Horizonte: Nandyala, 2010.
} 
Autores tradicionais, definindo pós-colonialismo, usam o termo "colonial" para descrever o período pré-independência e os termos "moderno" ou "recente" para assinar o período após a emancipação política. Embora não haja um consenso sobre o conteúdo do termo "pós-colonialismo", Ashcroft, Griffiths e Tiffin (1991) o usam para descrever a cultura influenciada pelo processo imperial desde os primórdios da colonização até os dias de hoje.

É perceptível um contraste em relação às definições, mas independentemente dessa diferenciação, por haver uma grande preocupação quanto ao nacionalismo cultural e econômico, muitos grupos ou comunidades, desvencilhando-se do colonialismo, rejeitaram as definições expostas anteriormente, por acreditarem que o termo prejudicaria as questões norteadoras e específicas que os preocupavam.

Nessa perspectiva, o que vale salientar quanto à crítica pós-colonialista é sua postura diante da realidade atual, com o intuito de entender os passos dados pelo imperialismo e seus múltiplos influxos, seja em menor ou maior grau. Destaca Bonnici (2012, p. 20) ao comentar sobre a abordagem pós-colonialista e o que ela envolve:

[...] um constante questionamento sobre as relações entre a cultura e o imperialismo para a compreensão da política e da cultura na era da descolonização; o autoquestionamento do crítico, porque solapa as próprias estruturas do saber, ou seja, a teoria literária, a antropologia, a geografia eurocêntrica; engajamento do crítico, porque sua preocupação deve girar em torno da criação de um contexto favorável aos marginalizados e aos oprimidos, para a recuperação da sua história, da sua voz, e para a abertura das discussões acadêmicas para todos; [...].

Os pressupostos envolvidos na teoria pós-colonialista contribuem significativamente para o entendimento de como os povos imperialistas, no caso os europeus, atuavam em relação aos povos colonizados, confluindo em escritos pós-coloniais a revelação das práticas opressoras das metrópoles. Até meados do século 20 é percebível um laço afetivo das literaturas americanas ao padrão europeu, pois os escritores e escritoras estavam estreitamente enleados à Europa. Hoje, o alcance da crítica pós-colonialista aborda os prolongamentos do colonialismo e seus efeitos, desvelando as relações de poder, possibilitando, como aponta Bonnici (2010), "a abertura das discussões acadêmicas para todos".

\section{Concepções dos Estudos Culturais}

As novas formas de análises histórica, social e cultural acontecem conforme as exigências e mudanças ocorridas no tempo. Para tanto, as manifestações literárias são implicadas pelas discussões teóricas e intelectuais que rodeiam e caracterizam determinada época. Dessa forma, os Estudos Culturais surgem na década de 50 do século 20 na Grã-Bretanha, com o intuito, no que se refere à crítica literária, de levantar discussões para refletir sobre as concepções tradicionais vigentes e traçar um trabalho de direcionamento interpretativo, ou seja, abrir espaços para outras concepções de literatura.

Os Estudos Culturais nascem a partir do segundo pós-guerra da Inglaterra, que estava passando por processo de reestruturação e organização. A educação é a esfera na qual se inicia essa nova abordagem, conforme explica Cevasco (2009, p. 319):

Em 1944, um ato do Parlamento eleva para quatorze anos a idade mínima para deixar a escola e obriga o governo a prover escolas gratuitas para todos. No âmbito da educação militante, uma organização se destaca como o chão institucional onde 
vai se constituir a nova disciplina. Como convém a suas tintas democratizantes, os Estudos Culturais não começam em uma universidade de elite, mas em uma escola noturna para adultos, a Workers' Educational Association, destinada a prover os meios educacionais para a integração social dos trabalhadores.

Mudam-se as metodologias de ensino. Os professores das mais diversas áreas começam um trabalho no qual o estudante se torna ser ativo no processo. Os professores de literatura tiveram de expandir o ensino, por isso incluíram-se no currículo os meios de comunicação de massa. O objetivo era aproximar-se da sociedade atual, posto que ela vivia nesse contexto da valorização da imagem e da expansão dos meios de comunicação. Ao aplicar o ensino conforme a necessidade dos alunos, esperava-se que, por meio dos fenômenos culturais, adquirissem habilidades significativas para a transformação do meio em que viviam. Tais mudanças implicaram diretamente questões disciplinares e opções teóricas. Destaca Cevasco (2009):

Os novos tempos do pós-guerra pediam uma visão mais democrática e inclusiva de cultura e uma forma mais integrada de ver as formas culturais como articulações de processos sociais reais. [...] O diferencial dos Estudos Culturais é que se propõe a ver produção cultural e modo de vida social como diferentes manifestações de um mesmo impulso (p. 322).

A partir dessa perspectiva, a disciplina de literatura ganhou impulso e firmou-se em várias universidades. Stuart Hall foi um dos responsáveis por cumprir esse papel. Com características interdisciplinares e a preocupação voltada para os acontecimentos e mudanças atuais, os Estudos Culturais agregam estudos de textos de outra natureza e de outros meios de representação da realidade. Por isso, há a ampliação valorativa de gêneros, como romances vendidos em bancas, ficção científica, etc. "O cânone - lista do que são consideradas grandes obras - é rediscutido e expandido com a redescoberta de obras antes relegadas ao esquecimento escritas por mulheres, negros, homossexuais e outros" (CEVASCO, 2009, p. 323).

Nos anos 90 do século 20 a disciplina chega ao Brasil. Em diversas universidades existem programas de Estudos Culturais, por exemplo na UFRJ, USP, UFSC, entre outras. Já havia entre nós, contudo, uma forma de estudar a relação entre cultura e literatura. Um exemplo é o crítico Antonio Candido, que pensa em suas obras escritas a forte ligação entre literatura e sociedade, quando essas caminham juntas dentro de um processo dialético.

No contexto escolar, esse tipo de abordagem proporciona aos alunos/leitores identificarem-se genuinamente com os textos que leem, o que amplia as discussões sobre a realidade vivenciada pelos alunos, possibilitando ao texto dar sentido ao mundo, parafraseando Marisa Lajolo (2011, p. 12).

\section{Sobre as políticas públicas do ensino de literatura na escola}

As discussões anteriores são fundamentais para termos uma visão geral da transformação do termo e de como a literatura, enquanto disciplina, foi se inserindo no contexto escolar e universitário e, mais do que isso, evidenciar como, a depender da concepção que se tenha de literatura, as práticas no ensino podem se tornar elitistas e excludentes ou democráticas e inclusivas. 
Historicamente, o Ensino Médio, no Brasil, só passa a fazer parte da Educação Básica a partir da Lei de Diretrizes e Bases para a Educação - LDB - de 1996, que teoricamente tinha o objetivo de oferecer uma educação igualitária. Antes disso, essa modalidade de ensino não era prioridade. Ele só ganha visibilidade quando há uma grande procura no número de matrículas. De acordo com os Parâmetros Curriculares Nacionais para o Ensino Médio:

No Brasil, o Ensino Médio foi o que mais se expandiu, considerando como ponto de partida a década de 80. De 1988 a 1997, o crescimento da demanda superou 90\% das matrículas até então existentes. Em apenas um ano, de 1996 a 1997, as matrículas no Ensino Médio cresceram 11,6\%. É importante destacar, entretanto, que o índice de escolarização líquida neste nível de ensino, considerada a população de 15 a 17 anos, não ultrapassa 25\%, o que coloca o Brasil em situação de desigualdade em relação a muitos países, inclusive da América Latina (BRASIL, 1999, p. 6).

Quanto às intervenções em âmbito federal, podemos destacar os seguintes documentos contribuidores dessa discussão: os Parâmetros Curriculares Nacionais para o Ensino Médio - PCNEM - de 2000, as orientações que complementam os Parâmetros Curriculares Nacionais - PCN+- de 2002, as Orientações Curriculares Nacionais - OCN de 2006 e, mais atual, a Base Nacional Comum Curricular - BNCC -, documento homologado pela Portaria $n^{\circ} 1.570$ e publicado no D.O.U. de 21/12/2017.

Os dois primeiros documentos, ao abordar a Literatura, a tratam de forma agregada à disciplina de Língua Portuguesa, ou seja, a Literatura aparece de modo secundário, não tem o destaque que deveria, e é colocada como forma de ilustração introdutória para trabalhar disciplinas distintas. Já a OCN de 2006 é um documento que dá destaque à Literatura de maneira que os outros documentos não haviam dado, pois os conhecimentos de Língua Portuguesa e os conhecimentos de Literatura são separados e, por essa razão, o ensino da Literatura é visto com ênfase, conforme o texto do referido documento:

As orientações que seguem têm sua justificativa no fato de que os PNC do ensino médio, ao incorporarem no estudo da linguagem os conteúdos de Literatura, passaram ao largo dos debates que o ensino de tal disciplina vem suscitando, além de negar a ela a autonomia e a especificidades que lhe são devidas (BRASIL, 2006, p. 49).

Desta forma, o destaque que deve ser dado ao ensino da literatura no Ensino Médio merece um enfoque particular, bem como foi vista no documento da OCN, pois reconhece sua autonomia e especificidades e ressalta sua importância na formação do indivíduo.

Quanto ao último documento - BNCC -, a literatura ainda é colocada como campo dentro do componente curricular de Língua Portuguesa, que, por sua vez, está dentro da área da Linguagem. Também é possível notar, contudo, algum avanço quanto à colocação do ensino da literatura, uma vez que o documento dedica um texto para explicar o lugar central da literatura no ensino: 
Em relação à literatura, a leitura do texto literário, que ocupa o centro do trabalho no Ensino Fundamental, deve permanecer nuclear também no Ensino Médio. Por força de certa simplificação didática, as biografias de autores, as características de épocas, os resumos e outros gêneros artísticos substitutivos, como o cinema e as HQs, têm relegado o texto literário a um plano secundário do ensino. Assim, é importante não só (re)colocá-lo como ponto de partida para o trabalho com a literatura, como intensificar seu convívio com os estudantes (BRASIL, 2017, p. 491).

Com base nos documentos supracitados, percebemos que de quatro documentos oficiais apenas um trata de forma particular o ensino da literatura, dando um destaque merecido. Os outros a relegam a um papel secundário, minimizando sua função formadora mais profunda aos estudantes, ao promover uma nova visão de mundo. Esse espaço reduzido para a literatura deve-se à valorização de conhecimentos técnicos e práticos de uma educação voltada para o "mundo do trabalho", conforme preconiza a Lei de Diretrizes e Bases da Educação Nacional - LDB - em seu Artigo 1으, Parágrafo 20: "A educação escolar deverá vincular-se ao mundo do trabalho e à prática social" (BRASIL, 2018, p. 10). A Literatura, nessa visada, é abordada no seu aspecto conteudista e técnico, ou seja, ensinam-se sua histórica e suas características, mas o texto literário é pouco explorado.

De acordo com a OCN, a Literatura não trata apenas de sobrecarregar alunos com informações sobre épocas, estilos, características de escolas literárias, muito menos usá-la como objeto para atender necessidades de outras áreas; a Literatura tem sua própria particularidade, mas infelizmente seu espaço é reduzido. Neste trecho vale lembrar a obra A literatura em perigo, de Todorov (2009): o perigo não está na escassez de bons poetas ou ficcionistas, no esgotamento da produção ou da criação poética, mas na forma como a literatura chega até os jovens, desde a escola primária até a faculdade. É importante refletir de que maneira a literatura chega aos estudantes: Será que ela é um agente de conhecimento ou apenas está sendo passada para cumprir determinada carga horária?

É necessário ressaltar que ensinar Literatura não é apenas dar a conhecer os clássicos literários, fazer as leituras ou os estilos de determinada época. É necessário formar o aluno como leitor, ou seja, tornar o estudante uma pessoa letrada, capaz não somente de ler determinado texto, mas se apropriar da literatura como linguagem, como forma de entender a sociedade e formar sua visão de mundo. De acordo com as OCNs, "podemos pensar por letramento literário como estado ou condição de quem não apenas é capaz de ler poesia ou drama, mas dele se apropria efetivamente por meio da experiência estética, fruindo-o." (BRASIL, 2006, p. 55).

Vale destacar que nos documentos citados é explicitada a importância que o texto literário já teve na evolução histórica, sendo considerado um bem cultural de determinado grupo. Corroboram Fortes e Oliveira (2015), ao afirmarem que o texto literário, por muito tempo, ocupou papel de destaque na história da humanidade, visto como instrumento de ensino do bem falar, do escrever e do poder de convencimento. $O$ ensino da literatura era privilégio da classe com poder aquisitivo maior, a educação não era oferecida para todos e estudar era considerado luxo. Fortes e Oliveira (2015) destacam, entretanto, que, ao se assegurar o direito à educação para todos, não ocorre a demo- 
cratização ao acesso à literatura; pelo contrário, acontece um processo de inversão, isto é, a literatura é deixada à margem, e a classe marginalizada é inserida numa escola que oferece um ensino alicerçado num princípio técnico produtivista.

No ano de 1971, a LDB 5.692, ao se referir à área das linguagens, o ensino de literatura e língua apareciam de forma dicotomizada, logo o trabalho com a produção textual, os conceitos gramaticais e a Literatura, era visto como áreas separadas. Com a publicação dos PCNEMs de 2000, há a tentativa de se fazer uma discussão sobre a importância da Literatura, porém se observa pouco sucesso nas discussões acerca do ensino, uma vez que os documentos não norteiam como aplicar isso, pois a importância do texto literário ainda remete a algumas dúvidas sobre a relevância dele no ambiente e espaço escolar. Observamos então:

Muitos educadores poderão se perguntar onde está a Literatura, a gramática, a produção de texto escrito, as normas. Os conteúdos tradicionais foram incorporados por uma perspectiva maior, que é a linguagem, entendida como um espaço dialógico, em que os locutores se comunicam (BRASIL, 2000, p. 23).

Apesar de ocorrer a discussão em torno e sobre a valorização do texto literário, a literatura ainda é exposta neste documento apenas no plano teórico. Não há direcionamentos quanto às práticas efetivas na sala de aula; enquanto isso, a OCN e a BNCC já tomam novos rumos quando se trata do ensino de literatura. $O$ trabalho com a literatura, muitas vezes, é limitado às questões gramaticais e acontece de forma fragmentada, ou seja, para complementação de determinado conteúdo.

Vale ressaltar, ainda, que tanto os PCNEMs 2000 quanto a BNCC, ao tratar das competências e habilidades, fazem apenas uma referência quanto ao texto literário. $O$ PCNEM (2000) afirma que é preciso "recuperar, pelo estudo do texto literário, as formas instituídas de construção do imaginário coletivo, o patrimônio representativo da cultura e as classificações preservadas e divulgadas, no eixo temporal e espacial" (BRASIL, 2000, p. 24).

Percebemos, ainda, uma valorização voltada ao aspecto histórico, em que a literatura é pensada como patrimônio cultural e deve ser transmitida de geração a geração. $O$ PCNEM, contudo, faz críticas quanto ao ensino da literatura, pois muitas vezes está pautado numa visão historiográfica apenas, devemos ter um olhar cauteloso nesse ponto, pois a maneira que o professor conduz este ensino pode não satisfazer a necessidade da aprendizagem do aluno. $O$ documento lança a proposta de agregar gramática, produção textual e literatura, com o intuito de realizar uma prática de ensino caracterizado pelo diálogo e pela comunicação. A afirmação, entretanto, não é aprofundada e não fica bem clara a proposta quanto ao ensino da literatura. O documento não enfatiza este ensino; sua colocação fica em segundo plano, como podemos constatar a seguir:

O trabalho do professor centra-se no objetivo de desenvolvimento e sistematização da linguagem interiorizada pelo aluno, incentivando a verbalização da mesma e o domínio de outras utilizadas em diferentes esferas sociais. Os conteúdos tradicionais do ensino da língua, ou seja, nomenclatura gramatical e história da literatura, são deslocados para um segundo plano. $O$ estudo da gramática passa a ser uma estratégia para compreensão/interpretação/produção de textos e a literatura integra-se à área de leitura (BRASIL, 2000, p. 18). 
Não se percebe em nenhum momento a explanação sobre a questão reflexiva e humanizadora que o texto literário contém enquanto instrumento formador de indivíduos e leitores críticos. Ao contrário, percebemos uma maior valorização de questões gramaticais e, por esse motivo, o ensino da literatura fica desprivilegiado. Quanto aos textos literários, os documentos não apresentam caminhos de como deve ocorrer um trabalho efetivo com ele para que a ampliação do conhecimento seja significativa.

É preciso observar, ainda, que no PCNEM não fica claro o conceito de literatura, pois este comenta que o conceito do texto literário é algo discutível. O que acontece é um processo reducionista, posto que não se coloca em pauta o potencial dialógico discutido em diversas teorias da linguagem que se refletem sobre o termo literatura.

Quanto aos PCNs, esses apresentam o livro didático como a ferramenta principal que deve ser conduzida pelo professor, sem levar em consideração a importância de uma pesquisa mais ampla em virtude de uma aula mais completa e produtiva. Percebemos, no documento, que o livro didático é um material completo, como fica sugerido na seguinte passagem: "[...] ao tratar dos gêneros literários, pode trazer a discussão de modelos explicativos, de análises críticas e de hipóteses de relações causais, do contexto das Ciências Humanas ou das Ciências Naturais, encontrados com facilidade no material didático" (BRASIL, 2000, p. 18).

Os documentos explanados deveriam apresentar ações com finalidade de sanar algumas deficiências do ensino. É notório, contudo, que alguns ainda falham, principalmente quando se trata do termo Literatura; o professor tem autonomia para planejar suas aulas, por isso não pode simplesmente se apoiar no livro didático; ele é apenas um suporte para auxiliá-lo quanto aos conteúdos.

Nos PCN+ encontramos, ainda, contradições quanto ao objetivo do ensino de Literatura. Vejamos em Brasil (2000, p. 19):

A Literatura, particularmente, além de sua específica constituição estética, é um campo riquíssimo para investigações históricas realizadas pelos estudantes, (...) permitindo reencontrar o mundo sob a ótica do escritor de cada época e contexto cultural: Camões ou Machado de Assis; Cervantes ou Borges; Shakespeare ou Allan Poe; Goethe ou Thomas Mann; Dante ou Guareschi; Molière ou Stendhal (...). Alguns alunos poderão pesquisar, em romances ou em pinturas, a história dos esportes, dos transportes, das comunicações, dos recursos energéticos, da medicina, dos hábitos alimentares, dos costumes familiares, das organizações políticas.

A confusão ocorre pelo fato de que, em um primeiro momento, percebemos a valorização da questão histórica e, em um segundo, a preocupação voltada para os estilos de época (características comuns às obras de um determinado período que elucida tanto a cosmovisão dos autores da época quanto aponta para elementos do gosto no que se refere às artes). O que não fica evidente e claro é o objetivo principal do ensino de literatura, que é a utilização e o trabalho com o texto literário e as suas nuances expressivas.

O ensino da literatura nas escolas ainda se encontra muito voltado para os aspectos históricos e para os estilos de época, ou como fonte de pesquisa histórica, como frisado nos documentos oficiais. As políticas públicas voltadas para o ensino da literatura precisam ser renovadas e terem outro olhar, dando especial atenção para o principal 
objeto de ensino dessa área que, atrelada à Língua Portuguesa, acaba por se tornar mais um conteúdo a ser memorizado pelo aluno, tornando-se um peso. A escola deve renovar a visão que temos sobre o ensino de literatura, considerando sua especificidade de linguagem e finalidade artística.

\section{CONSIDERAÇÕES FINAIS}

O conceito de literatura sofreu suas modificações com o passar dos tempos. Apesar de algumas práticas tradicionais ainda prevalecerem, muito foi modificado, questionado e tomou rumos diferentes. A crítica literária abriu espaços para muitas abordagens do texto literário, ampliando o escopo de produções que passaram a ser objeto de suas pesquisas.

Dessa forma, entendemos que se ampliam também as possibilidades de abordagens do texto literário em sala de aula, de maneira a se cumprirem alguns dos pressupostos dos próprios estudos mais recentes da crítica literária, como os empreendidos pelos Estudos Culturais, a saber: a abertura para a representação de múltiplas vozes e manifestações culturais, a incorporação de culturas que historicamente foram excluídas e silenciadas. Os pontos colocados, contudo, nos levam a entender que o ensino da literatura ainda é limitado a simplificações, e, muitas vezes, constituído por um programa educacional direcionado ao que se exige em programas de vestibulares e concursos. Os livros são construídos sempre nos mesmos moldes: movimentos literários, partes de textos de obras literárias que se tornam pretexto para o estudo da gramática, exercícios, questionários, interpretações textuais, com perguntas direcionadas, cuja expectativa são as respostas únicas dos manuais do professor, que desconsideram a polissemia da linguagem literária.

Não excluímos a importância do livro didático como ferramenta pedagógica nas aulas do professor, porém a sua constituição não contribui de forma significativa no letramento literário do aluno. Os conteúdos ainda são muito fragmentados, reduzidos, muitas vezes, a questões gramaticais. Urge uma discussão mais aprofundada e prática acerca do ensino de literatura no Ensino Médio, posto que o que existe ainda pode se reduzir a nada. Neste caso, as políticas públicas para o ensino de literatura precisam sofrer revisões a ponto de colocar a disciplina em seu lugar de importância.

\section{REFERÊNCIAS}

ABREU, Márcia. Cultura letrada: literatura e leitura. São Paulo: Editora Unesp, 2006.

BONNICl, Thomas. Conceitos-chaves da teoria pós-colonial. Maringá, PR: Eduem, 2005.

BONNICl, Thomas. Teoria e crítica pós-colonialistas. In: BONNICl, Thomas; ZOLIN, Lúcia Osana. Teoria literária: abordagens históricas e tendências contemporâneas. 3. ed. Rev. e ampl. Maringá: Eduem, 2009. BONNICl, Thomas. O pós colonialismo e a literatura: estratégias de Leitura. Maringá: Eduem, 2000.

BONNICl, Thomas. O pós-colonialismo e a literatura: estratégia de leitura. 2. ed. Maringá: Eduem, 2012. BRASIL. Ministério da Educação. Orientações Curriculares Nacionais - OCN. 2006. Disponível em: http:// portal.mec.gov.br/seb/arquivos/pdf/book_volume_01_internet.pdf. Acesso em: 6 jan. 2019.

BRASIL. LDB: Lei de diretrizes e bases da educação nacional. 2. ed. Brasília: Senado Federal; Coordenação de Edições Técnicas, 2018. 58 p. Disponível em: http://www2.senado.leg.br/bdsf/bitstream/handle/ id/544283/lei_de_diretrizes_e_bases_2ed.pdf?sequence=1\&isAllowed=y. Acesso em: 10 maio. 2020.

BRASIL. Ministério da Educação. PCNEM. 2000. Disponível em: www.mec.gov.br. Acesso em: 6 set. 2019. BRASIL. Ministério da Educação. PCN+. 1999. Disponível em: www.mec.gov.br. Acesso em: 6 set. 2019. 


\section{\& Contexto}

BRASIL. Parâmetros Curriculares Nacionais para o Ensino Médio. Brasília, DF: MEC, 2010.

BRASIL. Ministério da Educação. Base nacional Comum Curricular. BNCC, 2017. Disponível em: www.mec. gov.br. Acesso em: 6 nov. 2019.

CEVASCO, Maria Elisa. Literatura e estudos culturais. In: BONNICI, Thomas; ZOLIN, Lúcia Osana. Teoria literária: abordagens históricas e tendências contemporâneas. Maringá: Eduem, 2009.

COMPAGNON, Antoine. O demônio da teoria: literatura e senso comum. 2. ed. Belo Horizonte: Editora UFMG, 2010.

EAGLETON, Terry. Teoria da literatura: uma introdução. 6. ed. São Paulo: Martins Fontes, 2006.

FORTES, R. A.; OLIVEIRA, V. S. O ensino de Literatura no Ensino Médio e os documentos oficiais. Contexto, Vitória, n. 27, 2015/1.

JOUVE, Vincent. Por que estudar literatura? São Paulo: Parábola, 2012.

LAJOLO, Marisa. Do mundo da leitura para a leitura do mundo. São Paulo: Ática, 2011. Livro digital.

TODOROV, Tzvetan. A literatura em perigo. Rio de Janeiro: Difel, 2009. 